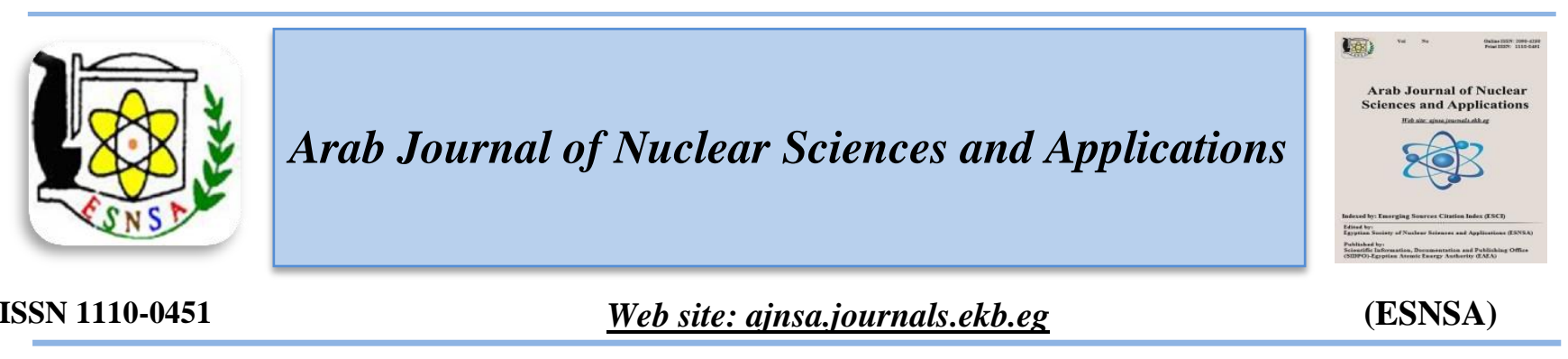

\title{
Development of Two Software Packages for Connecting with the MCNPX and NJOY Nuclear Codes to Directly Obtain and Extract Multi-Group Nuclear Cross Sections for Any Isotope
}

\author{
Seyed Alireza Mousavi Shirazi \\ Department of Physics, Faculty of Engineering, South Tehran Branch, Islamic Azad University, Tehran, Iran
}

\begin{abstract}
In this research, two software packages are developed to be connected with MCNP and NJOY to obtain and extract nuclear cross sections. The first (main) software package was coupled with the MCNPX code to automatically run it to obtain cross sections of isotopes for multi-group and a wide range of incident neutron energies. It was also coupled with the second software package entitled AutoNJOY, which is directly coupled with the NJOY code, to automatically run it and obtain the cross sections of isotopes at any temperature for any reaction. The results obtained by the AutoNJOY were automatically transferred to the first software package, and the results were compared with those obtained by the MCNPX code, and the graphs of isotope cross sections were plotted in energy. The first software package is also able to analyze the microscopic cross sections obtained by the AutoNJOY and draws the graph of the cross section vs. energy. It is also able to be connected to the ACE library directly and reads microscopic cross sections of all the elements and their isotopes that have the various ZAID. It was observed that from the thermal neutron range to the fast, the cross sections of isotopes obtained by the AutoNJOY were nearly similar to the results obtained by the first software package, and the derived graphs of both methods approved with each other.
\end{abstract}

Keywords: Cross Section; Isotope; MCNPX; NJOY; Software Package

\author{
Nomenclature \\ $\Sigma_{t}$ : Macroscopic total cross section in $\mathrm{cm}^{-1}$ \\ $\Sigma_{a}$ : Macroscopic absorption cross section in $\mathrm{cm}^{-1}$ \\ $\Sigma_{s}$ : Macroscopic scattering cross section in $\mathrm{cm}^{-1}$ \\ $\Sigma_{s_{I}}$ : Macroscopic elastic scattering cross section in $\mathrm{cm}^{-1}$ \\ $\Sigma_{s_{2}}$ : Macroscopic inelastic scattering cross section in $\mathrm{cm}^{-1}$ \\ $\Sigma(n, 2 n)$ : Macroscopic cross section of $(n, 2 n)$ reaction in $\mathrm{cm}^{-1}$ \\ $\Sigma(n, 3 n)$ : Macroscopic cross section of $(n, 3 n)$ reaction in $\mathrm{cm}^{-1}$ \\ $\sigma_{\text {fis }}:$ Microscopic fission cross section in Barn $\left(10^{-24} \mathrm{~cm}^{2}\right)$ \\ $X S$ : Cross section in $\mathrm{cm}^{-1}$ \\ $h$ : Heat production cross section (KERMA coefficient) in MeV/collision
}

Corresponding author: a moosavi@azad.ac.ir

DOI: 10.21608/ajnsa.2021.34629.1377

CScientific Information, Documentation and Publishing Office (SIDPO)-EAEA 


\section{Introduction}

Nowadays, in nuclear calculations, getting and extraction of both microscopic and macroscopic cross sections of isotopes is one of the most important matters in other nuclear calculations like reaction rate, power, and even dosimetry [1-2]. Nowadays for accessibility into crude data for microscopic cross sections, there are some of nuclear data centers and libraries such as "JENDL" that has versions 3.2, 3.3, 4.0, "JEFF" having versions 3.0, 3.1, 3.2, "CENDL" that has versions 2 and 3.1, "BROND-2.2", "IRDFF-1.05", "IAEA Standard 06" and "ENDF/B-VII.0" [3-5]. In the past, the MCNP code based on the Monte-Carlo method has been applied for getting the cross sections. The averaged cross sections and their uncertainties have also been got for the ENDF materials. Uncertainties are based on the ENDF/BVII.1, JEFF-3.1.2, JENDL-4.0 [6].

The software packages provided in the current research work is a development for nuclear codes to obtain one of the most important nuclear parameters that is nuclear cross section better, faster, and easier. In this research, two new nuclear software packages were designed by Delphi 7 programming language. The prime objective of designing these two software packages was that they would be able to make a linkage between the MCNPX and NJOY nuclear codes and automatically run them to obtain cross sections of isotopes for the various incident and multi-group neutron energies and also any temperature. Another goal was to make a comparison between the results and drawing some of the helpful and practical graphs including microscopic cross sections ((Barn)-E), macroscopic and heat production cross sections ((MeV/collision)-E) [78]. It also aimed to automatically obtain microscopic cross sections of any isotope for any reaction at any temperature and plot the graph of cross section (Barn) vs. energy (MeV) [9].

\section{Materials and Methods}

Obtaining material cross sections using the MCNPX code

For this purpose, the reaction rates of interactions such as absorption, scattering, first excited state, second excited state, and total macroscopic cross sections were produced using the MCNPX code for the elements for multi-group energies of the neutron. In addition to the reaction rates, the neutron fluxes were obtained for multi-group neutron energies.
In order, in the programming, 58 energy groups, which were quite arbitrary, were defined, and the mean values of macroscopic cross sections were obtained for them applying the Eq. 1 [10].

$$
\Sigma_{x}=\frac{\int_{g} \Sigma_{x} \varphi d E}{\int_{g} \varphi d E}
$$

Where:

$\Sigma_{x}(E)$ : Macroscopic cross section for an arbitrary reaction in $\mathrm{cm}-1$

$g$ : Energy group number $\left(i^{\text {th }}\right.$ group)

$\varphi(E)$ : the flux of neutron in $\mathrm{n} / \mathrm{cm} 2$.s

The number of incident neutron energies was arbitrary too. The input data defined for the Delphi 7 programming are shown as follows:

$$
\begin{gathered}
58 * \text { energy group interval } \\
1.0 \mathrm{e}-9 \\
\cdot \\
\cdot \\
\cdot \\
2.0 \mathrm{e}+1 \\
61 * \text { incident neutron energy } \\
1.0 \mathrm{e}-9 \\
\cdot \\
\cdot \\
\cdot \\
2.0 \mathrm{e}+1
\end{gathered}
$$

Programming by Delphi 7 language was carried out in a way that it was able to run the MCNPX automatically. It means that each of incident neutron energies was automatically set in front of "erg" in "sdef" card of the MCNPX input, and then the program was automatically run for this incident neutron energy, and the output file was stored as a directory and took the energy of incident neutron as a label. By clicking on the button "Run MCNP", the MCNPX code is automatically run $\mathrm{n}$ times in the number of incident neutron energies, and the related results were displayed. After that, the results were automatically saved in a folder named "MCNP Out" that was held up as the batch file in the Delphi 7 programming. This folder comprised many subfolders as a directory in the number of incident neutron energies, in a way that every subfolder consisted of the MCNPX programming run per defined incident neutron energy. The subfolders along with their labels are shown in Fig 1. 
The MCNPX is run with multi-group energies for a large number of optional incident neutron energies depending on what isotope that has its own ZAID (isotope identifier) is intended to be considered, and then the multi-group cross sections are obtained for the intended isotope and can be used for the next run of the MCNPX.

By pressing on the button "Run MCNP", the reaction rate of each of the defined energy groups was automatically computed by the MCNPX code and was then divided by the flux of its related group. In order, the macroscopic cross sections were obtained for every one of the energy groups taking into consideration that there was just one flux per one energy group. Then, the obtained data including, $\Sigma_{t}, \Sigma_{a}, \Sigma_{s}, \Sigma_{s_{1}}, \Sigma_{s_{2}}, \Sigma(n, 2 n)$, and $\Sigma(n, 3 n)$ were automatically inputted into the first software package from the MCNPX code. The cross sections of three materials including hydrogen, oxygen, and nitrogen for the first isotope of them obtained by the first software package are shown in Table 1. As the values of cross sections for 58 neutron energy groups are too long, the mentioned cross sections are only illustrated for the groups 1 and 58, respectively. In this research, as shown in Table 1, the scattering cross sections are provided as the outputs in the table format for any isotope and related energy group in a way that each of the energy groups and their intervals is assigned to the optional energies defined in the input data of the packages. So they are considered as data pairs like the outputs of the MCNP code. In order, the outputs of the packages tabulated in the data pair format can be accessible for another nuclear code like the CITATION.

The display of the first software package in the executive format is shown in Fig 2. As well, the graphs of both the total and absorption macroscopic cross sections for hydrogen $\left({ }_{1}^{1} \mathrm{H}\right)$ obtained by the MCNPX code are shown in the right-hand side of the display for a wide range of incident neutron energies.

Obtaining material cross sections using AutoNJOY software package

In this project, the material cross sections were obtained using the NJOY code as well as the MCNPX code. In order, another software package named "AutoNJOY" was also designed by Delphi 7 programming language to be connected to the NJOY code so that the material cross sections were automatically obtained. This software package is able to be coupled with the NJOY code to automatically run it to obtain cross sections of every isotope. The flowchart of applying two software packages is shown in Fig 3. The display of the second software package is shown in Fig 4.

Since both of the two software packages have been designed by Delphi 7 that is an object-oriented programming language, the second software package is connected to the first using a programming protocol and linkage to establish a connection between them in a way that both of which are interfaced with each other, and the data obtained by the MCNPX and NJOY nuclear codes are compared with one another, and visualized on the screen of the first software package. Of course, it should be taken into consideration that the batch files of both are placed in one folder, and to run each of the packages, both must be switched on and standby simultaneously to be able to establish a connection to transfer data as shown in Fig 3 (the related flowchart).

This software package is also able to be inputted for every isotope and arbitrary temperature. By clicking on the button "Read ENDF", the information of isotopes are read from the ENDF library, and when the arbitrary temperature entered the related field, through clicking on the "Run" button, the NJOY code is automatically run, and the new cross sections are generated at the arbitrary temperature. The new amounts of cross sections for the energies, which were not already existent in the ENDF library, are obtained through interpolation.

In the second software package, every time the new cross sections are generated based upon a new temperature, they are automatically added as new data to the xsdir file in the standard format of the ACE library meaning that the previous data in the xsdir file are updated, and more completed for a new temperature, and this procedure can be repeated for other temperatures consecutively.

Since the NJOY code uses the ENDF library and makes cross sections in the standard format of the ACE, getting the cross sections was carried out by interpolation on the existing energies in the ENDF library, and both the new energies and their correlated cross sections are obtained as new data pairs. The equations, which the NJOY code applies to Maxwellian and resonance spectrums, are according to Eqs 2, 3, respectively [11-12]. 


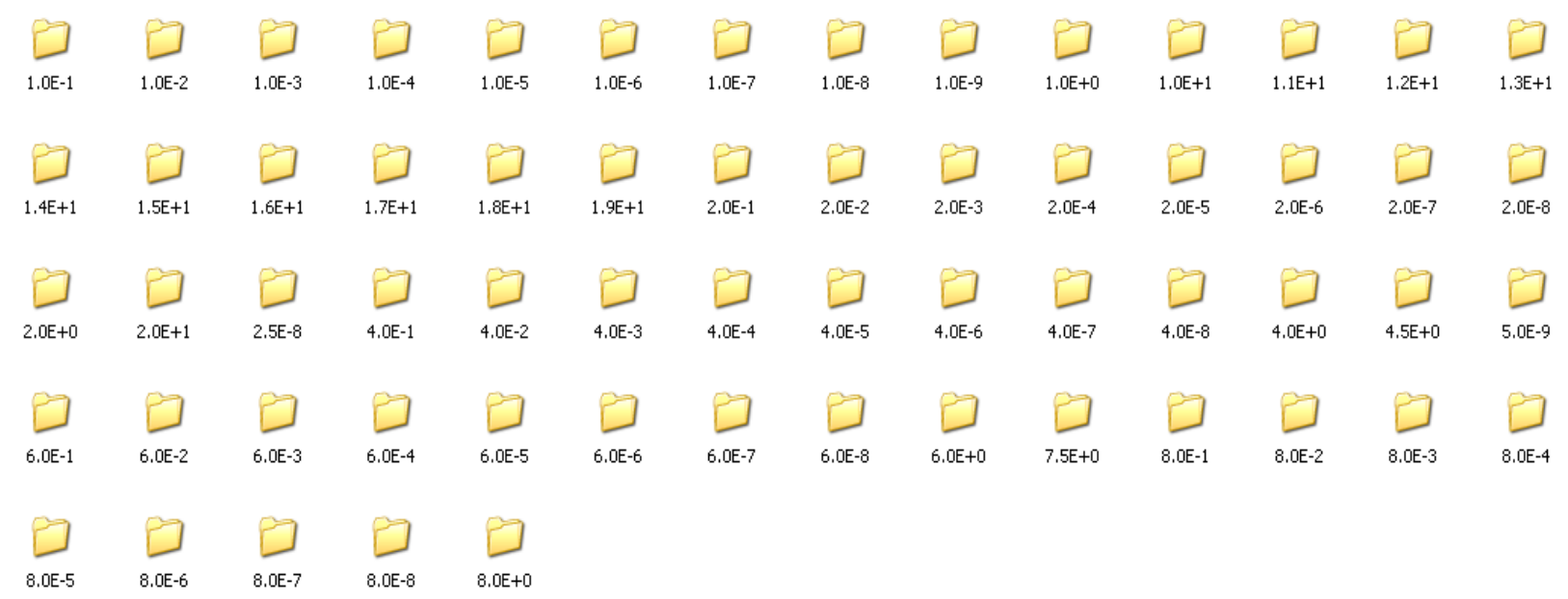

Fig.1: The generated subfolders along with their labels

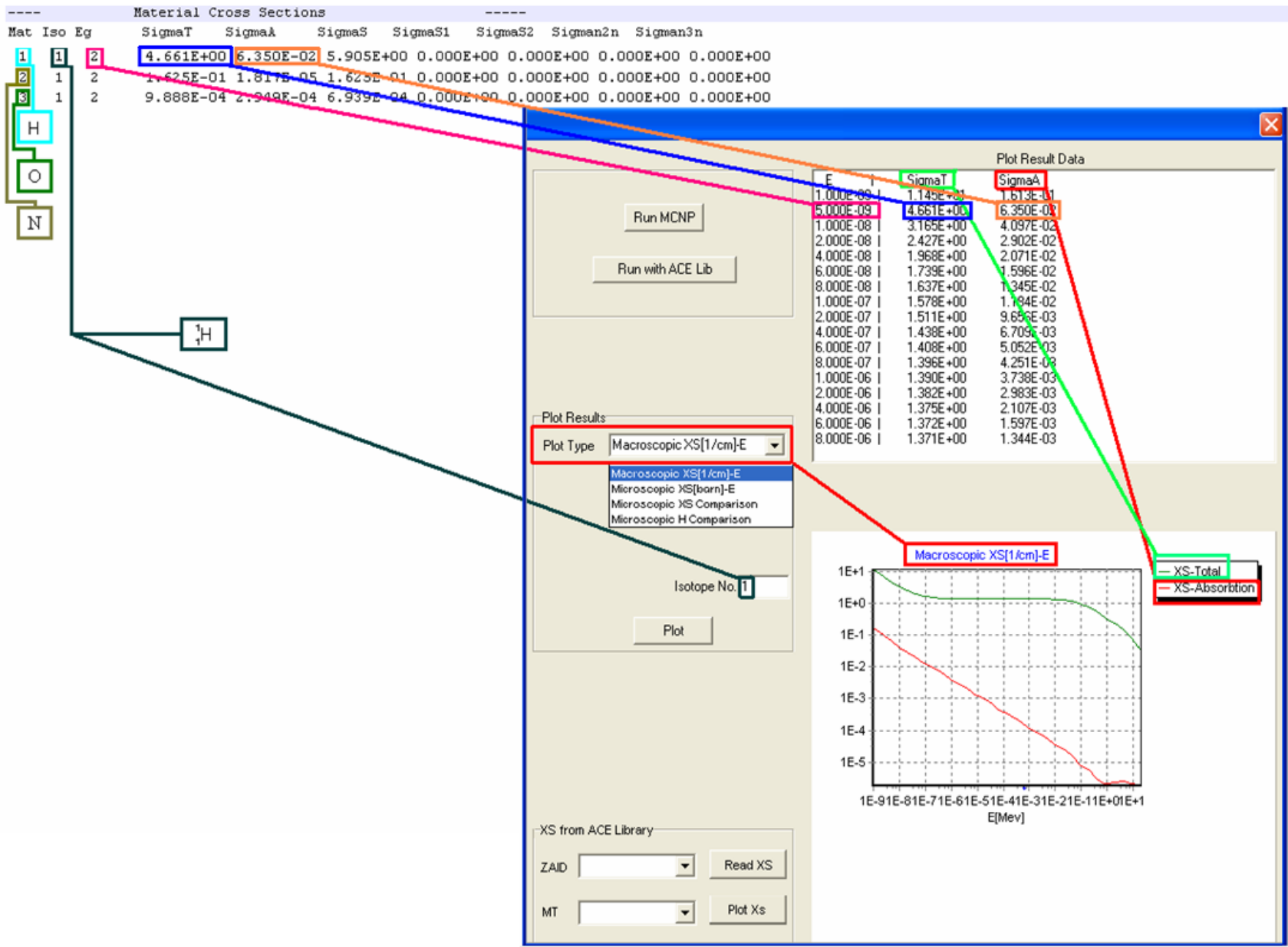

Fig.2 The display of the first software package illustrating both total and absorption microscopic cross sections for hydrogen $\left({ }_{1}^{1} H\right)$ 
Table (1): The obtained cross sections of materials

\begin{tabular}{|c|c|c|c|c|c|c|c|c|c|}
\hline Material & $\begin{array}{l}\text { Isotope } \\
\text { number }\end{array}$ & $\begin{array}{l}\text { Energy } \\
\text { group }\end{array}$ & $\Sigma_{t}\left(\mathrm{~cm}^{-1}\right)$ & $\Sigma_{a}\left(\mathrm{~cm}^{-1}\right)$ & $\Sigma_{s}\left(\mathrm{~cm}^{-1}\right)$ & $\begin{array}{c}\sum_{s_{1}} \\
\left(\mathrm{~cm}^{-1}\right)\end{array}$ & $\begin{array}{c}\Sigma_{s_{2}} \\
\left(\mathrm{~cm}^{-1}\right)\end{array}$ & $\begin{array}{c}\Sigma(n, 2 n) \\
\left(\mathrm{cm}^{-1}\right)\end{array}$ & $\begin{array}{c}\Sigma(n, 3 n) \\
\left(\mathrm{cm}^{-1}\right)\end{array}$ \\
\hline $1(\mathrm{H})$ & 1 & 1 & $1.14 \mathrm{E}+01$ & $1.61 \mathrm{E}-01$ & $1.12 \mathrm{E}+01$ & $0.00 E+00$ & $0.00 \mathrm{E}+00$ & $0.00 E+00$ & $0.00 E+00$ \\
\hline $2(0)$ & 1 & 1 & $2.93 \mathrm{E}-01$ & 4.61E-05 & $2.93 \mathrm{E}-01$ & $0.00 E+00$ & $0.00 E+00$ & $0.00 \mathrm{E}+00$ & $0.00 E+00$ \\
\hline $3(N)$ & 1 & 1 & 1.90E-03 & $6.94 \mathrm{E}-04$ & $1.21 \mathrm{E}-03$ & $0.00 \mathrm{E}+00$ & $0.00 \mathrm{E}+00$ & $0.00 \mathrm{E}+00$ & $0.00 \mathrm{E}+00$ \\
\hline$\cdot$ & . & . & . & . & · & . & . & . & . \\
\hline . & . & . & . & . & . & . & . & . & . \\
\hline . & . & . & . & • & . & • & . & • & • \\
\hline $1(\mathrm{H})$ & 1 & 58 & $3.23 \mathrm{E}-02$ & $1.82 \mathrm{E}-06$ & $3.23 \mathrm{E}-02$ & $0.00 \mathrm{E}+00$ & $0.00 \mathrm{E}+00$ & $0.00 \mathrm{E}+00$ & $0.00 E+00$ \\
\hline $2(0)$ & 1 & 58 & $5.48 \mathrm{E}-02$ & $4.03 E-03$ & $3.35 \mathrm{E}-02$ & $7.72 \mathrm{E}-05$ & $2.21 \mathrm{E}-03$ & 7.64E-05 & $0.00 E+00$ \\
\hline $3(N)$ & 1 & 58 & $8.34 \mathrm{E}-05$ & $7.89 \mathrm{E}-06$ & $5.47 \mathrm{E}-05$ & $1.70 \mathrm{E}-07$ & $3.28 \mathrm{E}-07$ & $5.50 \mathrm{E}-07$ & $0.00 \mathrm{E}+00$ \\
\hline
\end{tabular}

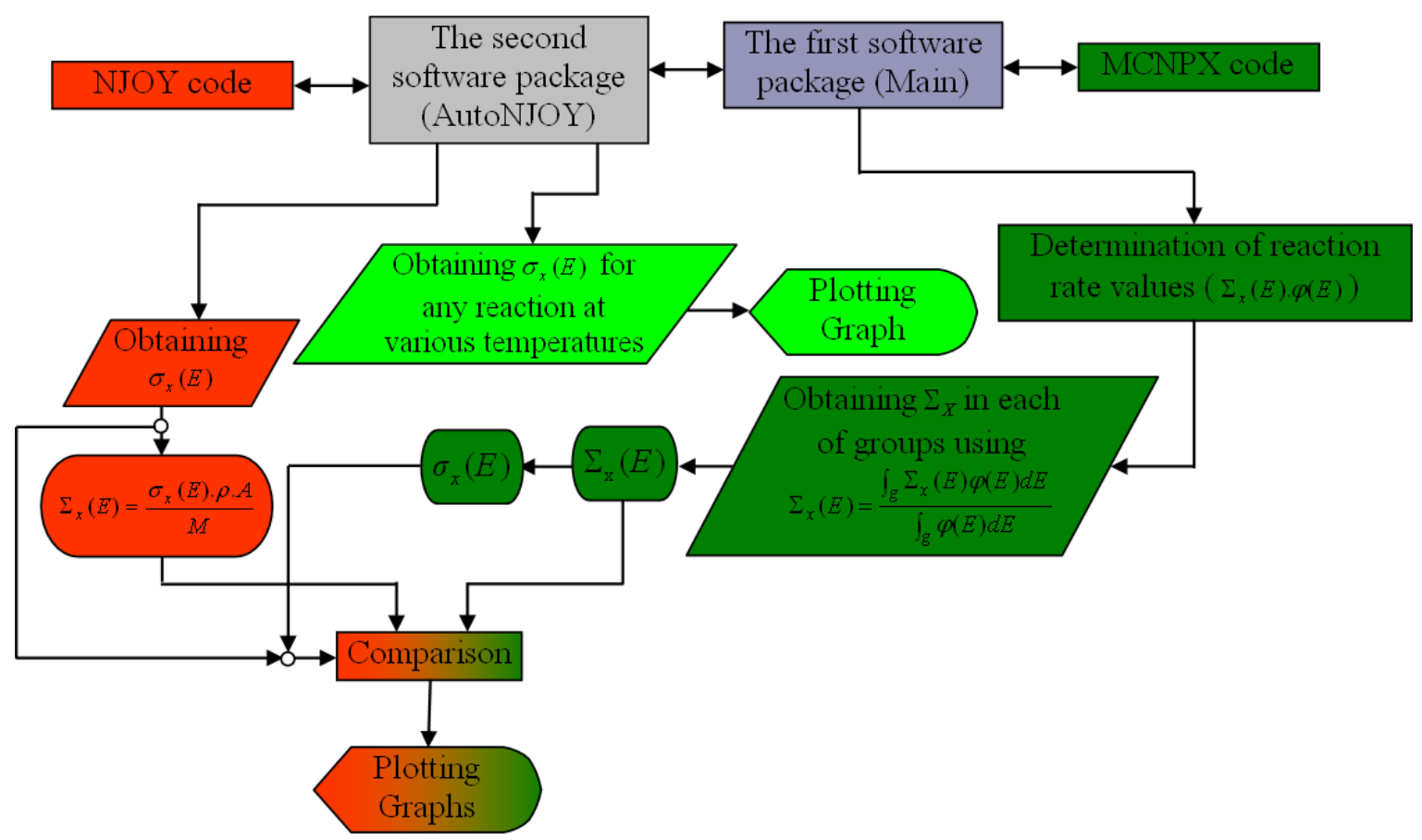

Fig (3): The flowchart of applying two software packages and their linkages for obtaining nuclear cross sections

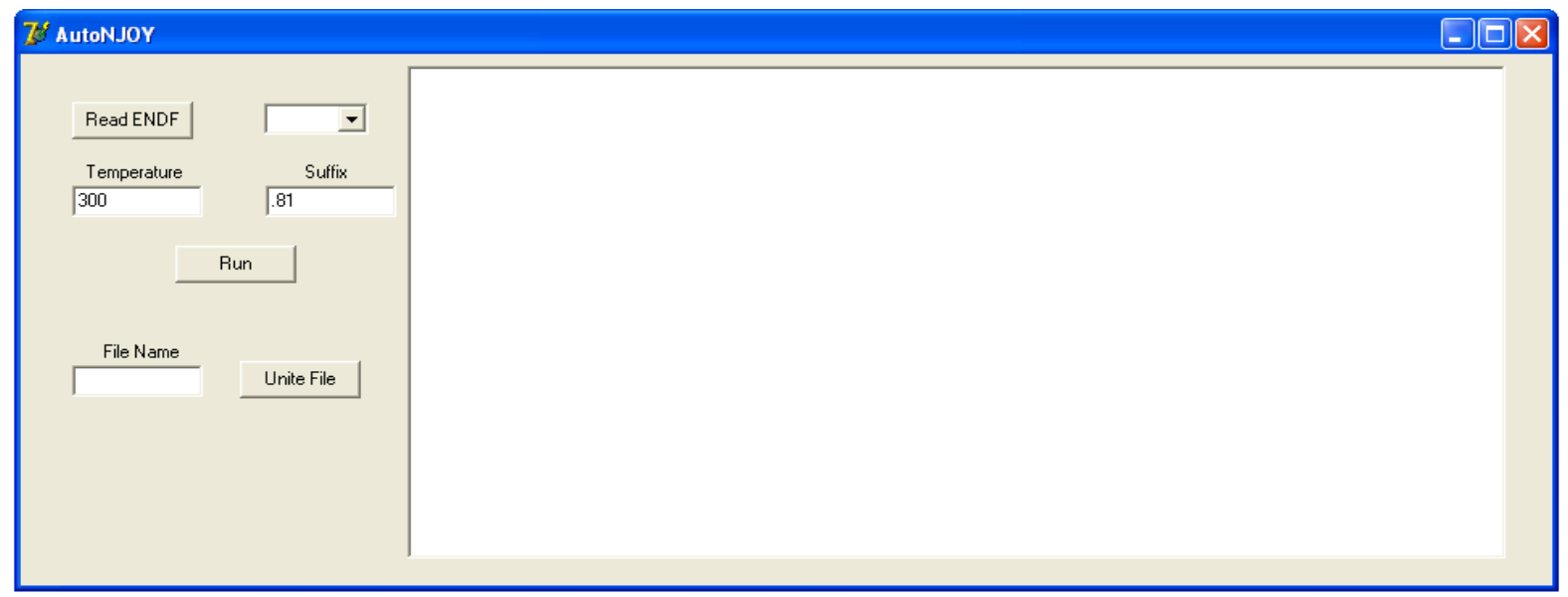

Fig (4): The display of the second software package to automatically run the NJOY code Arab J. Nucl. Sci. \&Applic. Vol. 54, No. 1 (2021) 


$$
\begin{gathered}
\sigma_{\max }(T)=\frac{2}{\sqrt{\pi}} \frac{\int_{E_{L}}^{E_{U}} \sigma(E, T) \cdot E \cdot \exp \left(\frac{-E}{k T}\right) d E}{\int_{E_{L}}^{E_{U}} E \cdot \exp \left(\frac{-E}{k T}\right) d E} \\
\sigma_{\text {res }}(T)=\int_{E_{L}}^{E_{U}} \sigma(E, T) \cdot \frac{1}{E} d E
\end{gathered}
$$

Where:

$\sigma_{\max }(T)$ : Microscopic cross section for Maxwellian spectrum in Barn
$\sigma(E, T)$ : Microscopic cross section for an arbitrary temperature and incident neutron energy in Barn $T$ : Temperature in Kelvin

$k$ : the Boltzmann constant $\left(1.38 \times 10^{-23} \mathrm{~m}^{2} \mathrm{~kg} \mathrm{~s}^{-2} \mathrm{~K}^{-1}\right)$ $E_{U}$ : Upper limit of integration for neutron energy in $\mathrm{eV}$

$E_{L}$ : Lower limit of integration for neutron energy in $\mathrm{eV}$

$\sigma_{r e s}(T)$ : Microscopic cross section for resonance spectrum in Barn

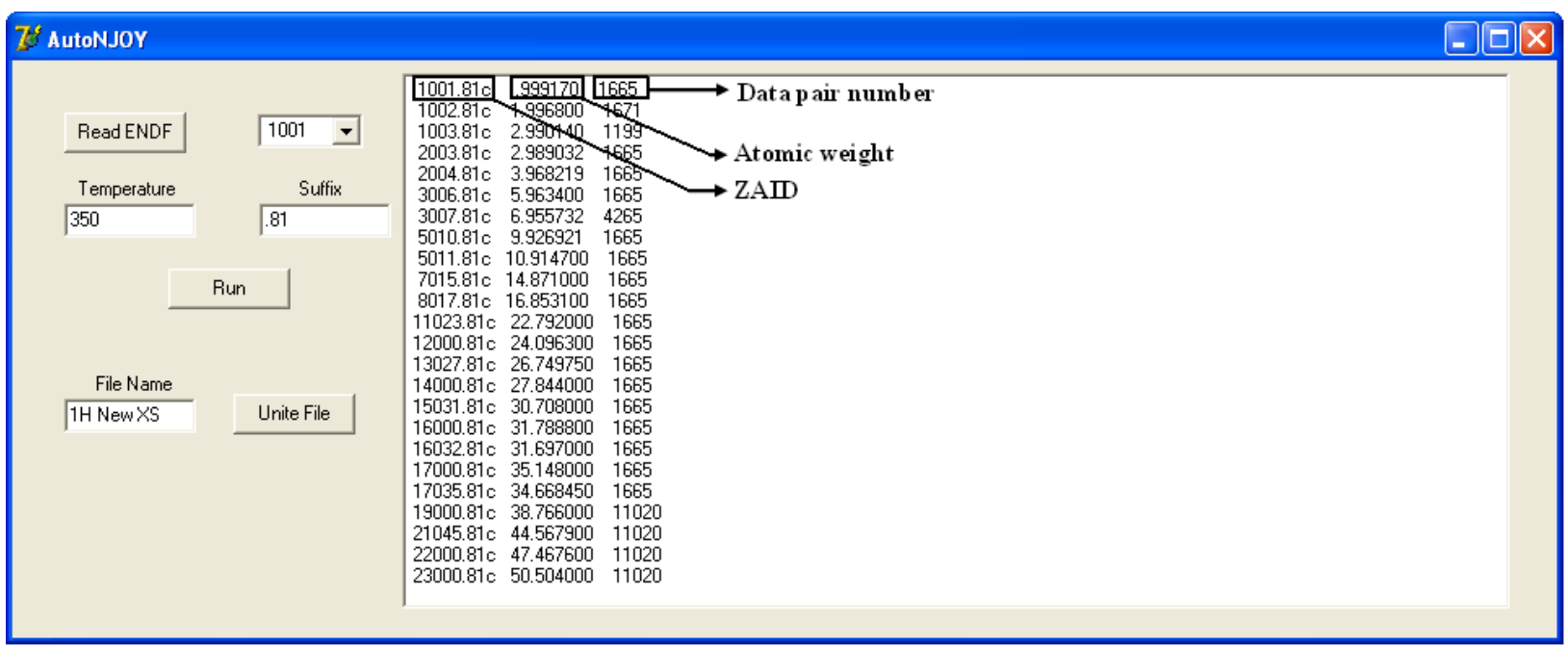

Fig (5): The display of AutoNJOY software package while running the NJOY code for obtaining the new cross sections of an isotope of hydrogen at a temperature of $350 \mathrm{~K}$

The display of the AutoNJOY software package (while running the NJOY code and extraction of the new cross sections) in the executive format is shown in Fig 5.

After that, by clicking on the button "Unite File", the new cross sections of the considered isotope are consolidated to one file which was named in the section of "File Name". In this stage, the characteristics of the isotope at an arbitrary temperature, which entered the AutoNJOY software package, are automatically copied from the generated directory entitled "Newdir.out" among the batch files of the NJOY code and is pasted in the "xsdir" file belonging to the batch files of the first software package. For instance, the characteristics of one of the hydrogen isotopes are obtained at an arbitrary temperature.

In order, the generated cross sections of this isotope were hereafter used for the first software package. By clicking on the button "Run with the ACE Lib" (according to Fig 2), the cross sections obtained by the NJOY code at an arbitrary temperature were transferred from the second software package (AutoNJOY) to the first software package of this research, and these cross sections were finally compared with those obtained by the MCNPX code.

The first software package is also able to read and analyze the microscopic cross sections of an isotope, which were obtained by the AutoNJOY at an arbitrary temperature, and plot the graph of cross section (Barn) vs. energy (MeV). The selection of every element and its isotopes that have various ZAID (isotope identifier having atomic number-mass number is made through clicking on the button "Read XS" (cross section, and then the ZAID of isotopes appear according to Fig 6 . 


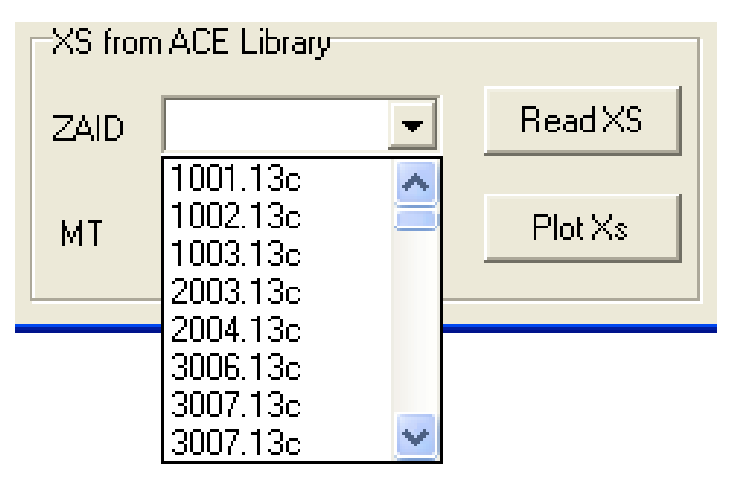

Fig (6): The isotopes getting visible on the screen

There is another caption on this screen named "MT" in a way that by clicking on the button "Plot XS", the reaction numbers of isotopes all appear. These reaction numbers describe the type of arbitrary cross sections. For instance, clicking on "-2, 1" causes microscopic cross sections of absorption and total to be illustrated, respectively. It is illustrated in Fig 7.

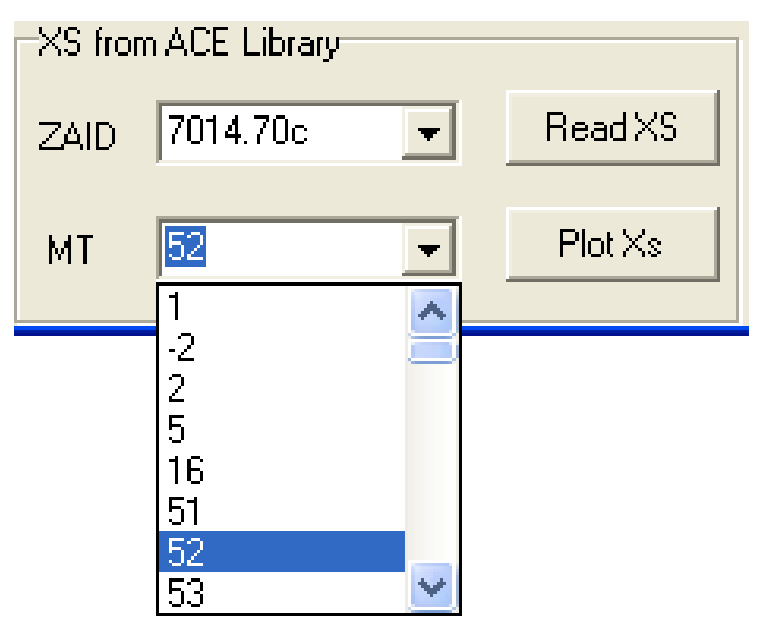

Fig (7): The reaction numbers getting visible on the screen

\section{RESULTS AND DISCUSSION}

In this study, the results obtained by the two methods were compared with each other. The microscopic cross sections and heat production cross section (h) for some of the materials like oxygen, hydrogen, and nitrogen obtained by the two software packages are illustrated in Figs. 8-11 for a wide range of incident neutron energies. In this research, 61 incident neutron energies were considered. As shown in the related flowchart (Fig 3 ), the flux averaged cross sections obtained by the MCNPX reaction rates (through the Equation 1) are compared with those obtained by the second software package applying NJOY code in the standard format of the ACE library.

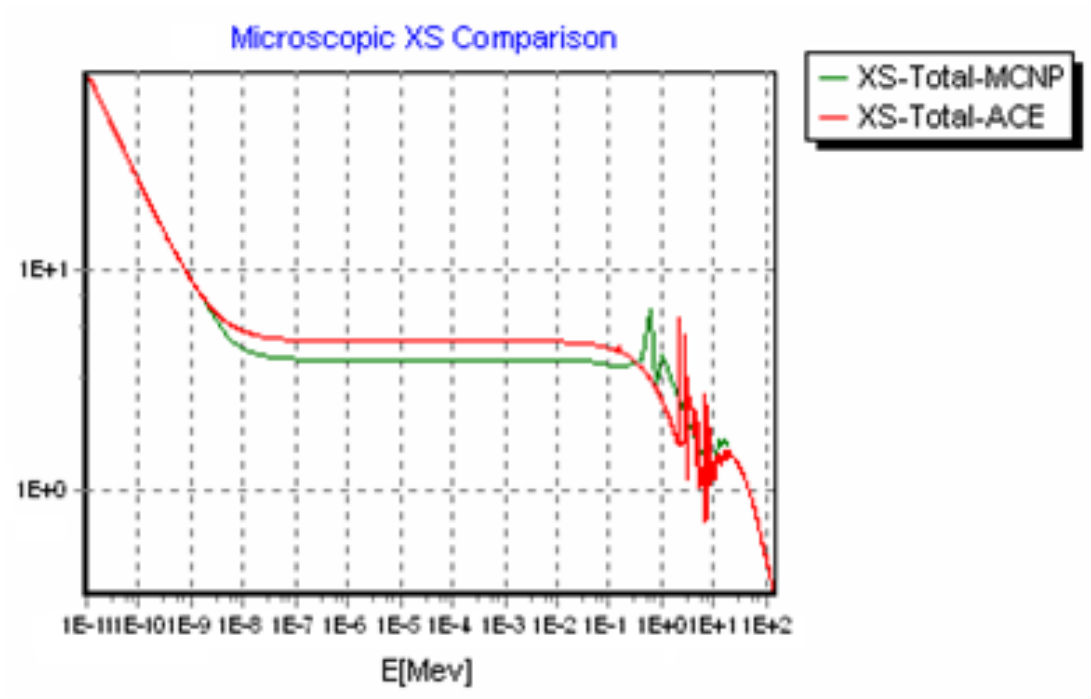

Fig (8): The graphs of total microscopic cross sections for oxygen obtained by the first software package through coupling the MCNPX code with the NJOY code 


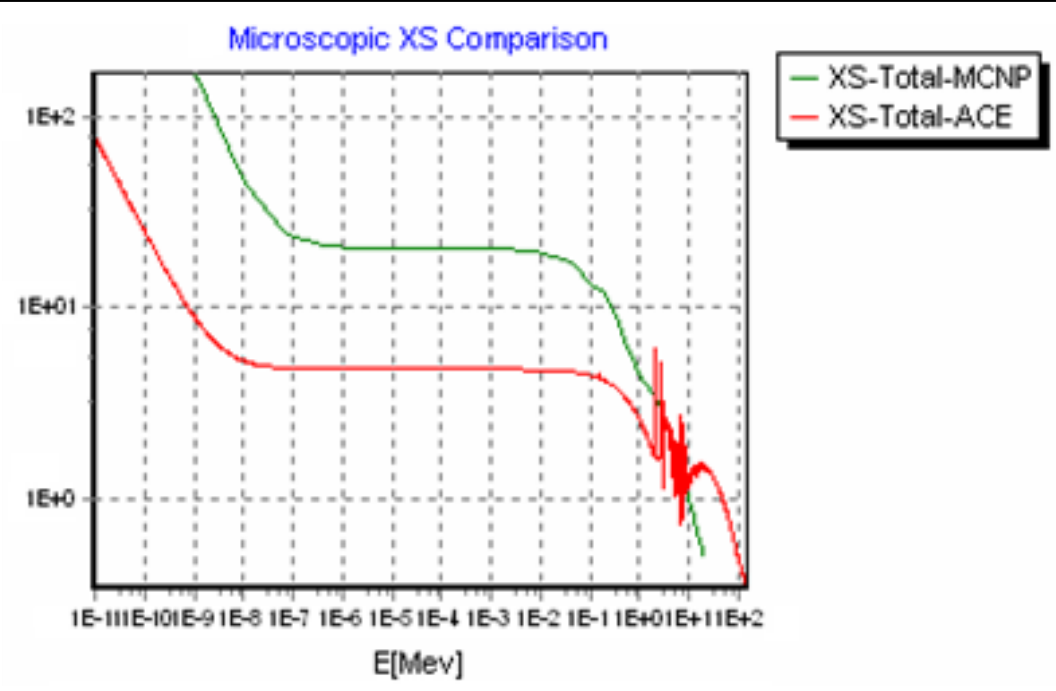

Fig (9): The graphs of total microscopic cross sections for hydrogen obtained by the first software package through coupling the MCNPX code with the NJOY code

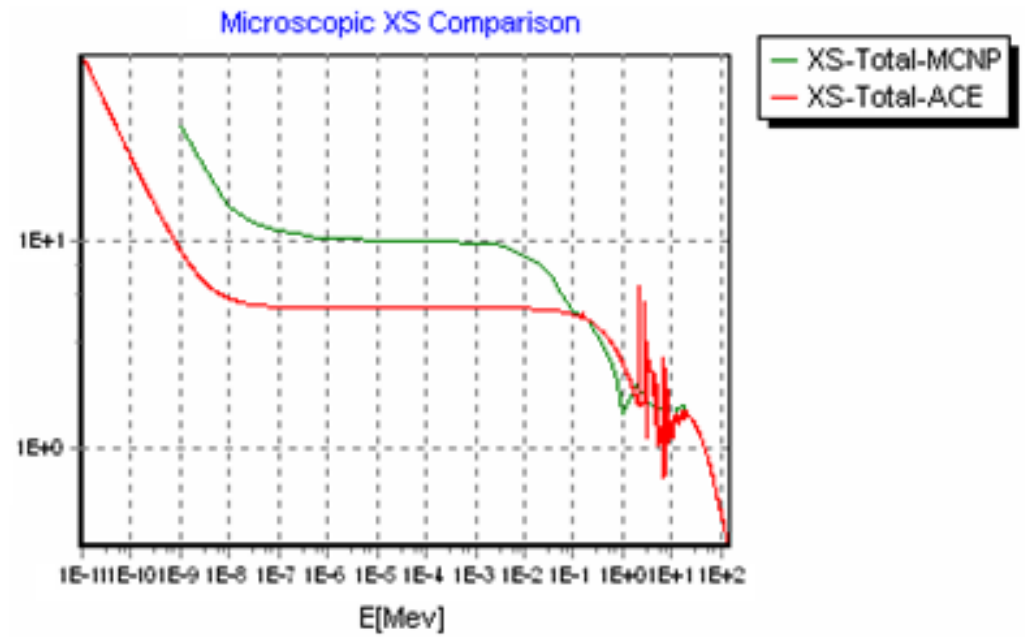

Fig (10): The graphs of total microscopic cross sections for nitrogen obtained by the first software package through coupling the MCNPX code with the NJOY code
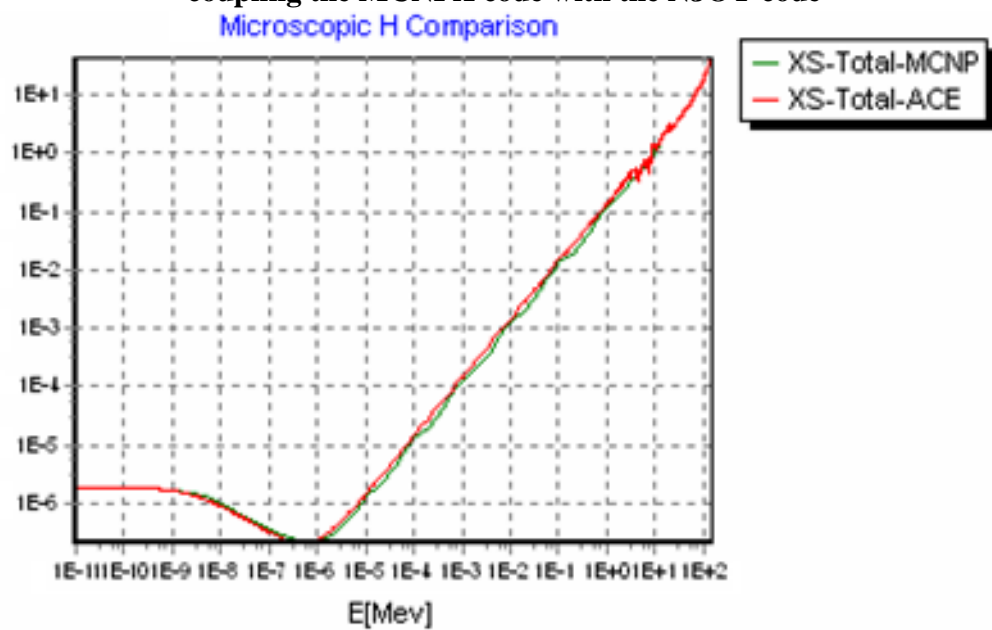

Fig (11): The graphs of $h$ for nitrogen obtained by the first software package through coupling the MCNPX code with the NJOY code. 
According to Figures 8-11, it is observed that from thermal neutron range to the fast, the results obtained by the two software packages are nearly similar to each other, and the derived graphs approve with one another. But, there are some differences and variations between the comparisons. The reason of the difference between two green and red graphs is that the multi-group cross sections obtained by the first software package applying the MCNPX code (through the Equation 1) were taken into account just for 58 energy groups (green graphs) while in the red graphs, the multi-group cross sections obtained by the second software package (applying NJOY code) were obtained for a large number of existing energy groups of the ENDF library. The solution for the elimination of the discrepancy between the obtained results is increasing the number of energy

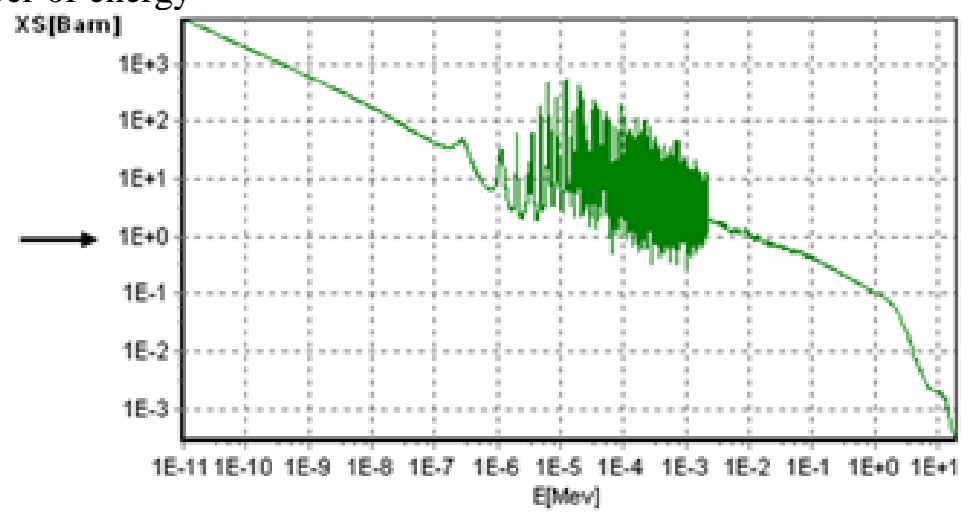

Fig (12): Microscopic absorption cross sections for one of the uranium isotopes with ZAID "92235.70c" at $300 \mathrm{~K}$ plotted by the first software package

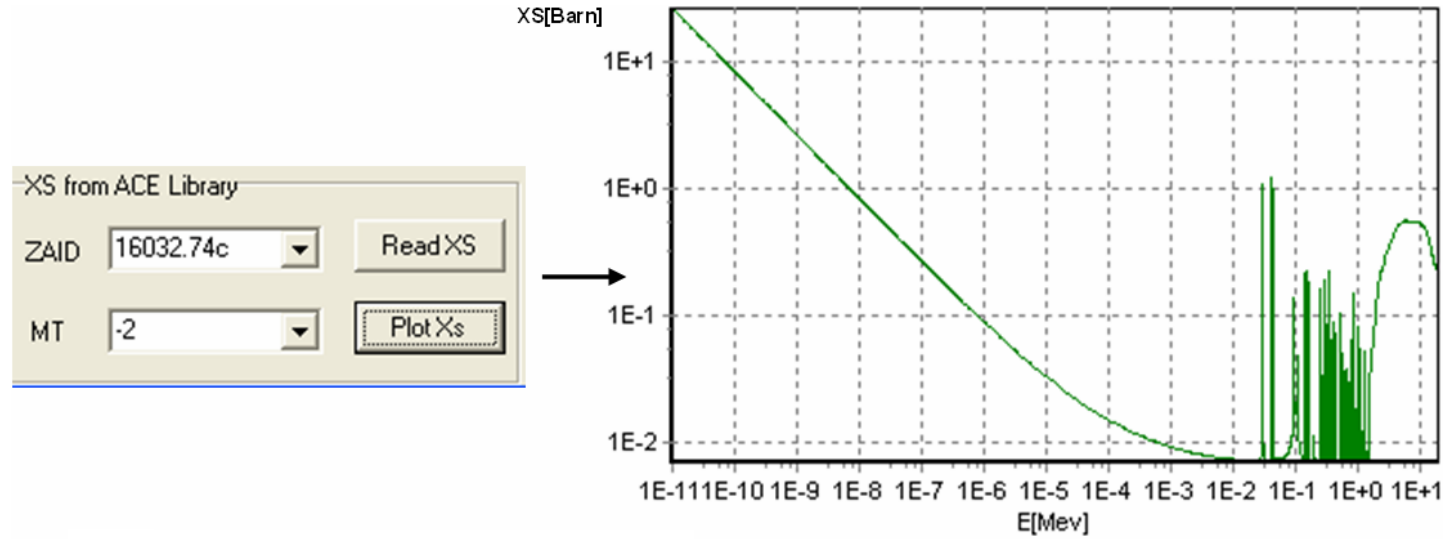

Fig (13): Microscopic absorption cross sections for one of the sulfur isotopes with ZAID " $16032.74 \mathrm{c}$ " at $400 \mathrm{~K}$ plotted by the first software package 


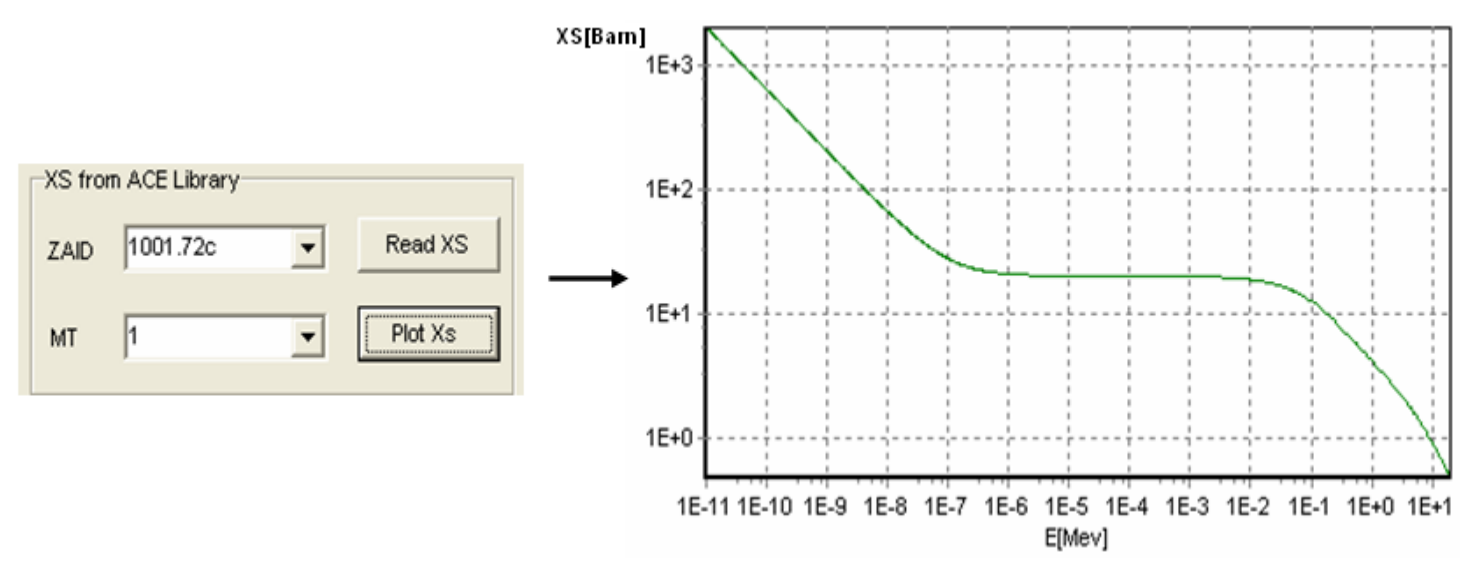

Fig (14): Microscopic total cross sections for one of the hydrogen isotopes with ZAID "1001.72c" at $350 \mathrm{~K}$ plotted by the first software package

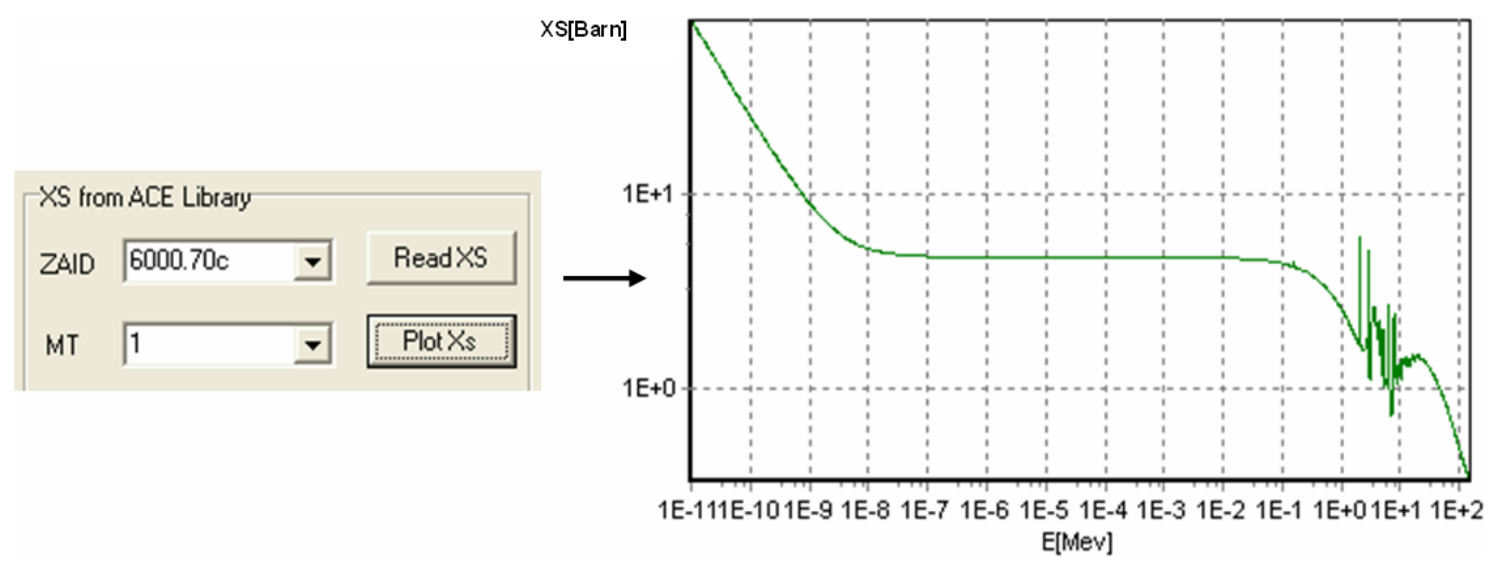

Fig (15): Microscopic total cross sections for one of the carbon isotopes with ZAID " $6000.70 \mathrm{c}$ " at $500 \mathrm{~K}$ plotted by the first software package

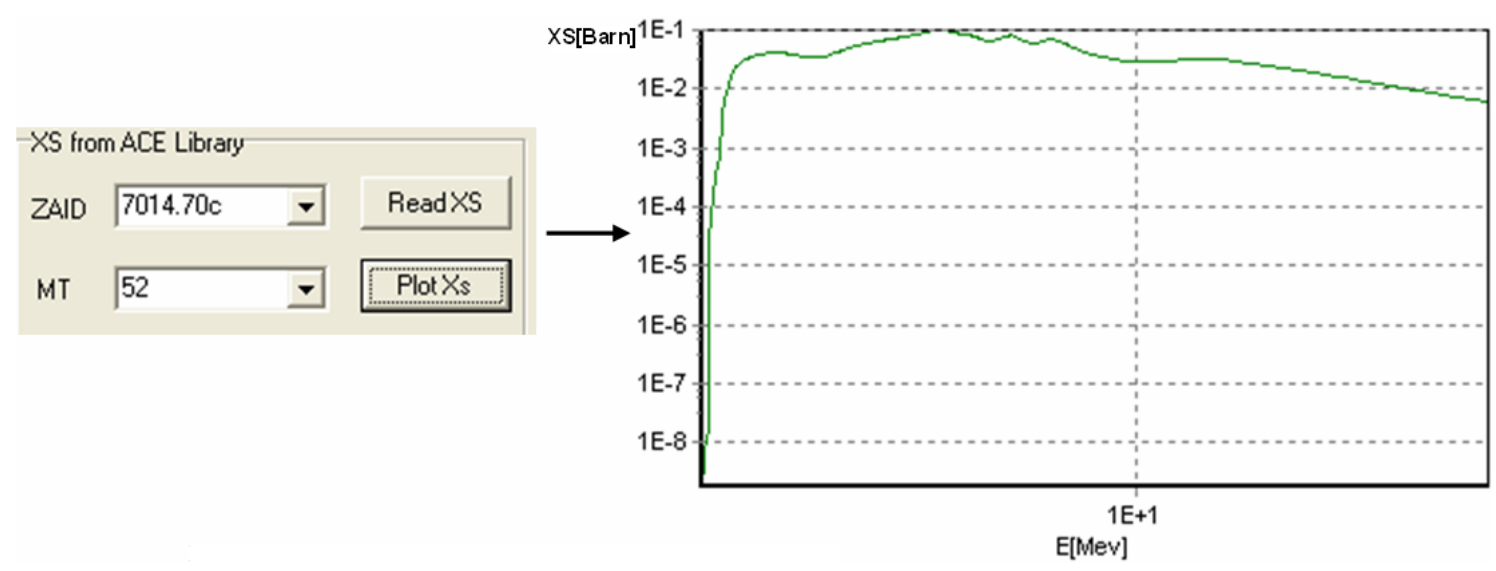

Fig (16): Microscopic cross sections of $(\mathrm{n}, 3 \mathrm{n})$ reaction for one of the nitrogen isotopes with ZAID "7014.70c" at $800 \mathrm{~K}$ plotted by the first software package 


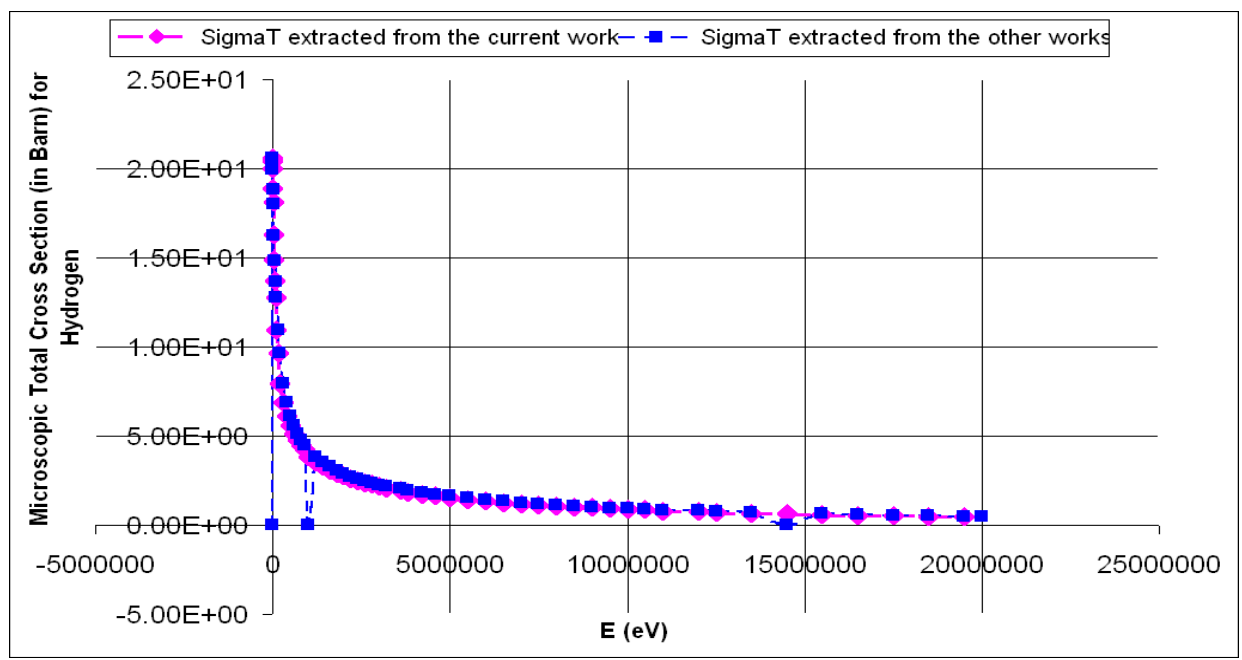

Fig (17): The microscopic total cross sections for hydrogen at $300 \mathrm{~K}$ obtained by the current work and extracted from the other works

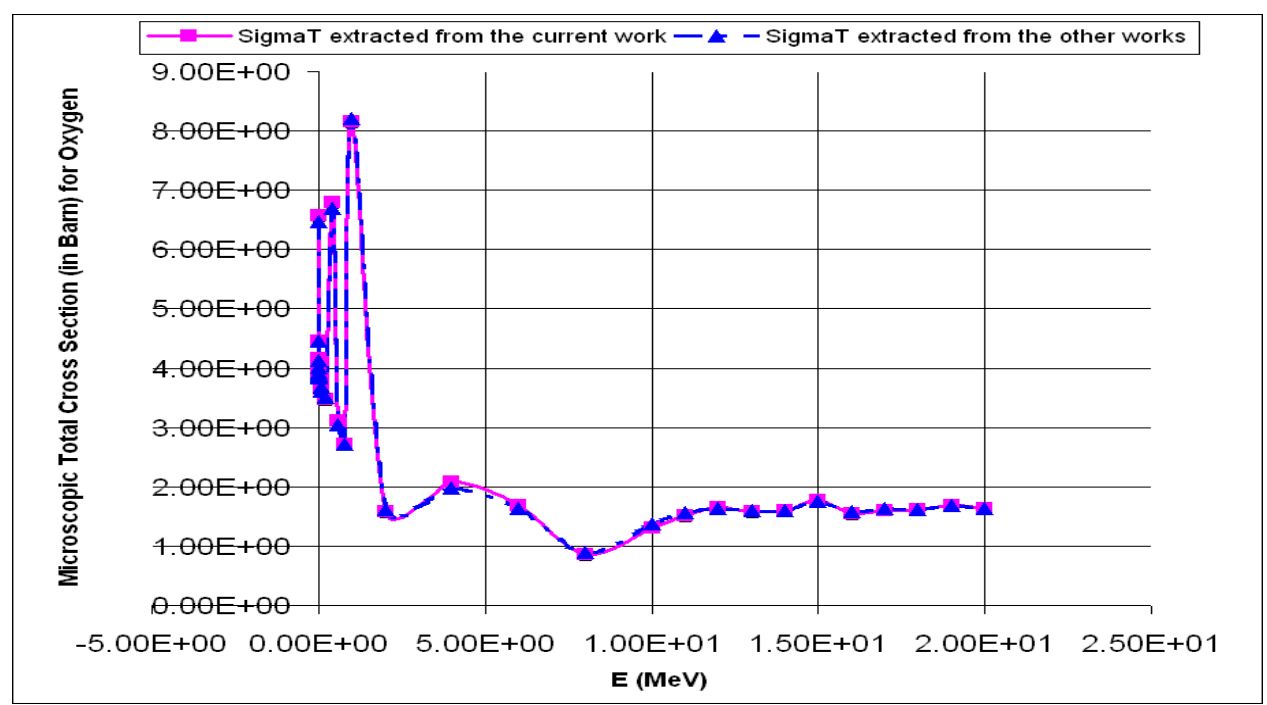

Fig (18): The microscopic total cross sections for oxygen at $300 \mathrm{~K}$ obtained by the current work and extracted from the other works

In this section, the results obtained in the current work were compared to those obtained by other previous works [13-14]. Figs. 17 and 18 illustrate the microscopic total cross sections for one of the isotopes of hydrogen and oxygen at $300 \mathrm{~K}$, respectively [15-16].

As observed in Figs. 17 and 18, the microscopic total cross sections for one of the isotopes of hydrogen and oxygen obtained in the current work match perfectly with those extracted from other works within the thermal to the fast neutron energy range, and their curves overlap well with each other.

The differences (plus-minus) of the results are also shown in Tables 2 and 3. 
Table (2): The microscopic total cross sections of hydrogen extracted from the current work and the other works and comparison between the results

\begin{tabular}{|c|c|c|c|}
\hline $\begin{array}{l}\text { The energy of Neutron } \\
\qquad(\mathrm{eV})\end{array}$ & $\begin{array}{l}\sigma_{t} \text { extracted from the } \\
\text { current work (Barn) }\end{array}$ & $\begin{array}{c}\sigma_{t} \text { extracted from the } \\
\text { other works (Barm) }\end{array}$ & $\begin{array}{l}\text { Plus-Minus of the current work } \\
\text { compared to the other works }\end{array}$ \\
\hline 0.00001 & $1.18 \mathrm{E}+03$ & 1190.027 & $-1.30 \mathrm{E}+01$ \\
\hline 0.00001094 & $1.13 E+03$ & 1133.425 & $-7.42 \mathrm{E}+00$ \\
\hline 0.00001219 & $1.07 \mathrm{E}+03$ & 1079.624 & $-1.36 \mathrm{E}+01$ \\
\hline 0.00001344 & $1.02 \mathrm{E}+03$ & $1.03 \mathrm{E}+03$ & $-1.23 E+01$ \\
\hline 0.00001438 & $9.82 E+02$ & 979.4698 & $2.43 E+00$ \\
\hline 0.00001625 & $9.24 \mathrm{E}+02$ & 932.8909 & $-9.29 E+00$ \\
\hline 0.00001812 & $8.75 E+02$ & $8.89 E+02$ & $-1.41 E+01$ \\
\hline 0.00002 & $8.33 \mathrm{E}+02$ & 846.3568 & $-1.39 \mathrm{E}+01$ \\
\hline 0.00002375 & $7.64 \mathrm{E}+02$ & $7.68 \mathrm{E}+02$ & $-3.86 E+00$ \\
\hline 0.00002656 & $7.23 E+02$ & 731.4214 & $-8.92 \mathrm{E}+00$ \\
\hline 0.00003219 & $6.56 \mathrm{E}+02$ & $6.64 \mathrm{E}+02$ & $-7.19 E+00$ \\
\hline 0.00003875 & $5.98 \mathrm{E}+02$ & 602.0675 & $-3.77 E+00$ \\
\hline 0.0000425 & $5.71 \mathrm{E}+02$ & $5.73 E+02$ & $-2.15 E+00$ \\
\hline 0.00004813 & $5.37 E+02$ & 546.2552 & $-9.36 \mathrm{E}+00$ \\
\hline 0.00005156 & $5.19 \mathrm{E}+02$ & 520.2992 & $-1.60 E+00$ \\
\hline 0.0000625 & $4.71 E+02$ & 472.084 & $-8.84 \mathrm{E}-01$ \\
\hline 0.00006875 & $4.49 \mathrm{E}+02$ & 449.7055 & $-4.05 E-01$ \\
\hline 0.00007813 & $4.22 \mathrm{E}+02$ & $4.28 \mathrm{E}+02$ & $-6.75 E+00$ \\
\hline 0.00008438 & $4.06 \mathrm{E}+02$ & 408.0518 & $-2.35 \mathrm{E}+00$ \\
\hline 0.0001031 & $3.67 \mathrm{E}+02$ & $3.70 E+02$ & $-3.27 E+00$ \\
\hline 0.0001125 & $3.52 \mathrm{E}+02$ & 352.7033 & $-1.20 \mathrm{E}+00$ \\
\hline 0.000125 & $3.34 \mathrm{E}+02$ & 336.0057 & $-2.51 E+00$ \\
\hline 0.0001375 & $3.18 \mathrm{E}+02$ & $3.20 E+02$ & $-2.07 E+00$ \\
\hline 0.00015 & $3.05 E+02$ & 304.9295 & $-4.30 \mathrm{E}-01$ \\
\hline : & : & : & : \\
\hline : & : & $\vdots$ & : \\
\hline 4200000 & $1.83 \mathrm{E}+00$ & $1.83 \mathrm{E}+00$ & 1.73E-04 \\
\hline 4600000 & $1.72 \mathrm{E}+00$ & 1.721156 & $-1.56 \mathrm{E}-04$ \\
\hline 5000000 & $1.62 \mathrm{E}+00$ & 1.622358 & $-3.58 \mathrm{E}-04$ \\
\hline 5500000 & $1.51 \mathrm{E}+00$ & $1.51 \mathrm{E}+00$ & 4.07E-04 \\
\hline 6000000 & $1.42 \mathrm{E}+00$ & 1.418196 & $-1.96 \mathrm{E}-04$ \\
\hline 6500000 & $1.33 \mathrm{E}+00$ & 1.333747 & $2.53 \mathrm{E}-04$ \\
\hline 7000000 & $1.26 \mathrm{E}+00$ & $1.26 \mathrm{E}+00$ & $-4.04 \mathrm{E}-04$ \\
\hline 7500000 & $1.19 \mathrm{E}+00$ & 1.177793 & $1.32 \mathrm{E}-02$ \\
\hline 8000000 & $1.13 \mathrm{E}+00$ & 1.117065 & $1.29 \mathrm{E}-02$ \\
\hline 8500000 & $1.07 \mathrm{E}+00$ & $1.06 \mathrm{E}+00$ & $1.21 \mathrm{E}-02$ \\
\hline 9000000 & $1.02 \mathrm{E}+00$ & 1.011669 & $1.13 \mathrm{E}-02$ \\
\hline 9500000 & $9.77 \mathrm{E}-01$ & 0.9656373 & $1.15 \mathrm{E}-02$ \\
\hline 10000000 & $9.34 \mathrm{E}-01$ & $9.23 \mathrm{E}-01$ & $1.11 \mathrm{E}-02$ \\
\hline 10500000 & 8.95E-01 & 0.8843188 & $1.08 \mathrm{E}-02$ \\
\hline 11000000 & $8.59 E-01$ & 0.8482309 & $1.05 \mathrm{E}-02$ \\
\hline 12000000 & 7.94E-01 & $8.05 \mathrm{E}-01$ & $-1.11 \mathrm{E}-02$ \\
\hline 12500000 & 7.64E-01 & 0.7545846 & $9.62 \mathrm{E}-03$ \\
\hline 13500000 & 7.11E-01 & 0.7112158 & $-1.58 \mathrm{E}-05$ \\
\hline 15500000 & $6.23 \mathrm{E}-01$ & 0.6261576 & $-3.06 \mathrm{E}-03$ \\
\hline 16500000 & $5.86 \mathrm{E}-01$ & 0.5878048 & $-1.70 \mathrm{E}-03$ \\
\hline 17500000 & $5.53 \mathrm{E}-01$ & 5.53E-01 & $-4.60 \mathrm{E}-06$ \\
\hline 18500000 & $5.23 \mathrm{E}-01$ & 0.5227642 & $3.58 \mathrm{E}-05$ \\
\hline 19500000 & 4.96E-01 & 0.489132 & 6.37E-03 \\
\hline 20000000 & 4.83E-01 & $4.83 \mathrm{E}-01$ & 1.62E-05 \\
\hline
\end{tabular}


Table (3): The microscopic total cross sections of oxygen extracted from the current work and the other works and comparison between the results

\begin{tabular}{|c|c|c|c|}
\hline $\begin{array}{l}\text { The energy of neutron } \\
\text { (MeV) }\end{array}$ & $\begin{array}{c}\sigma_{t} \text { extracted from the } \\
\text { current work (Barn) }\end{array}$ & $\begin{array}{c}\sigma_{t} \text { extracted from the other } \\
\text { works (Barm) }\end{array}$ & $\begin{array}{l}\text { Plus-Minus of the current work } \\
\text { compared to the other works }\end{array}$ \\
\hline 1.00E-09 & $6.57 \mathrm{E}+00$ & $6.48 \mathrm{E}+00$ & $9.42 \mathrm{E}-02$ \\
\hline 5.00E-09 & $4.47 \mathrm{E}+00$ & $4.45 \mathrm{E}+00$ & $1.05 \mathrm{E}-02$ \\
\hline $1.00 \mathrm{E}-08$ & $4.16 \mathrm{E}+00$ & $4.12 \mathrm{E}+00$ & $3.59 E-02$ \\
\hline $2.00 \mathrm{E}-08$ & $4.01 \mathrm{E}+00$ & $4.01 \mathrm{E}+00$ & $-1.26 \mathrm{E}-03$ \\
\hline $3.90 \mathrm{E}-08$ & $3.93 E+00$ & $3.92 \mathrm{E}+00$ & $6.22 \mathrm{E}-03$ \\
\hline $6.02 \mathrm{E}-08$ & $3.90 \mathrm{E}+00$ & $3.89 E+00$ & $9.85 \mathrm{E}-03$ \\
\hline $1.00 \mathrm{E}-07$ & $3.88 \mathrm{E}+00$ & $3.87 \mathrm{E}+00$ & $1.42 \mathrm{E}-02$ \\
\hline $2.00 \mathrm{E}-07$ & $3.87 E+00$ & $3.85 E+00$ & $1.50 \mathrm{E}-02$ \\
\hline $1.00 \mathrm{E}-06$ & $3.86 \mathrm{E}+00$ & $3.84 \mathrm{E}+00$ & $1.22 \mathrm{E}-02$ \\
\hline 7.50E-02 & $3.69 \mathrm{E}+00$ & $3.68 \mathrm{E}+00$ & $1.24 \mathrm{E}-02$ \\
\hline $1.00 \mathrm{E}-01$ & $3.64 \mathrm{E}+00$ & $3.61 E+00$ & $3.03 E-02$ \\
\hline $2.00 \mathrm{E}-01$ & $3.48 \mathrm{E}+00$ & $3.50 \mathrm{E}+00$ & $-2.75 E-02$ \\
\hline $4.00 \mathrm{E}-01$ & $6.80 E+00$ & $6.70 E+00$ & $9.52 \mathrm{E}-02$ \\
\hline $6.00 \mathrm{E}-01$ & $3.11 \mathrm{E}+00$ & $3.04 \mathrm{E}+00$ & $6.47 \mathrm{E}-02$ \\
\hline $8.00 \mathrm{E}-01$ & $2.72 E+00$ & $2.71 E+00$ & $1.01 \mathrm{E}-02$ \\
\hline $1.00 \mathrm{E}+00$ & $8.15 E+00$ & $8.20 E+00$ & $-4.73 E-02$ \\
\hline $2.00 \mathrm{E}+00$ & $1.58 \mathrm{E}+00$ & $1.62 \mathrm{E}+00$ & $-3.54 \mathrm{E}-02$ \\
\hline $4.00 E+00$ & $2.08 \mathrm{E}+00$ & $1.98 \mathrm{E}+00$ & $9.90 \mathrm{E}-02$ \\
\hline $6.00 \mathrm{E}+00$ & $1.69 \mathrm{E}+00$ & $1.64 \mathrm{E}+00$ & $5.00 \mathrm{E}-02$ \\
\hline $8.00 E+00$ & $8.65 \mathrm{E}-01$ & 8.93E-01 & $-2.76 \mathrm{E}-02$ \\
\hline $1.00 \mathrm{E}+01$ & $1.32 \mathrm{E}+00$ & $1.37 \mathrm{E}+00$ & $-5.93 E-02$ \\
\hline $1.10 \mathrm{E}+01$ & $1.51 \mathrm{E}+00$ & $1.56 \mathrm{E}+00$ & $-5.45 E-02$ \\
\hline $1.20 \mathrm{E}+01$ & $1.65 \mathrm{E}+00$ & $1.64 \mathrm{E}+00$ & $1.26 \mathrm{E}-02$ \\
\hline $1.30 \mathrm{E}+01$ & $1.58 \mathrm{E}+00$ & $1.59 \mathrm{E}+00$ & $-7.98 \mathrm{E}-03$ \\
\hline $1.40 \mathrm{E}+01$ & $1.59 \mathrm{E}+00$ & $1.61 \mathrm{E}+00$ & $-1.64 \mathrm{E}-02$ \\
\hline $1.50 \mathrm{E}+01$ & $1.77 \mathrm{E}+00$ & $1.76 \mathrm{E}+00$ & $3.22 \mathrm{E}-03$ \\
\hline $1.60 \mathrm{E}+01$ & $1.55 E+00$ & $1.58 \mathrm{E}+00$ & $-2.63 E-02$ \\
\hline $1.70 \mathrm{E}+01$ & $1.61 \mathrm{E}+00$ & $1.64 \mathrm{E}+00$ & $-3.04 \mathrm{E}-02$ \\
\hline $1.80 \mathrm{E}+01$ & $1.62 \mathrm{E}+00$ & $1.62 \mathrm{E}+00$ & $2.82 \mathrm{E}-03$ \\
\hline $1.90 \mathrm{E}+01$ & $1.69 \mathrm{E}+00$ & $1.69 \mathrm{E}+00$ & $4.69 \mathrm{E}-03$ \\
\hline $2.00 \mathrm{E}+01$ & $1.64 \mathrm{E}+00$ & $1.64 \mathrm{E}+00$ & $-9.35 E-04$ \\
\hline
\end{tabular}

\section{Conclusion}

The designed two software packages can be put into operation for all nuclear calculations in nuclear reactors and medical radiation and plotting the related graphs. These two software packages may be at the cutting edge of fast and easy getting isotope cross sections through coupling two renowned nuclear codes. Firstly, one of the features of these two software packages is that the number of multi-group cross sections is quite optional, and to obtain the multi-group cross sections during a short period of time, the energy intervals are adaptable to change. Secondly, because of the definite need for obtaining multigroup cross sections as a data bank for nuclear calculations and applying them in some fields such as neutronics, nuclear reactors, medical radiation, dosimetry, etc, generation of them plays a very preponderant role in the aforementioned scopes. Besides, the existing cross sections in the libraries like ENDF are not complete, and they are considered just as crude data and particularly for $300 \mathrm{~K}$. As well, there is often a long interval between two energies particularly for high energies, and it causes a large number of cross sections are unspecified, but through this project, the cross sections for multiple incident neutron energies and also multi-group energies, which have not been specified in such libraries, can be interpolated and specified, and one is able to obtain an unspecified cross section for optional energy at any temperature. Another matter is to avoid running and extracting multi-group cross sections manually.

Moreover, it should be taken into account that one of the main goals of this research was designing a facility to fast and easy obtaining isotope cross sections by two methods for any reaction at any temperature and comparing the results and directly plotting the extracted graphs. 
Through applying these two software packages, the procedure of generating isotope cross sections is automatically performed, and it does not need to be carried out manually. As described in the manuscript, the procedures of running the MCNPX code for obtaining multi-group cross sections, obtaining various isotope cross sections such as, and at any temperature and automatically adding them as new data to the xsdir file in the standard format of the ACE library, data transferring for comparing the results, and directly plotting the graphs are automatically done.

\section{References}

1. Makhloul, M., Boukhal, H., El Bardouni, T., Kaddour, M., Chakir, E and et al. (2018) 235 U elastic cross-section adjustment in criticality benchmarks - Comparison between JENDL-4.0 and ENDF/-VII.1, Ann. Nucl. Energy, 114, 541550.

2. Koštál, M., Cvachovec, F., Jánský, B., Rypar, V., Jurríček, $V$ and et al. (2016) Neutron deep penetration through reactor pressure vessel and biological concrete shield of VVER-1000 Mock-Up in LR-0 reactor, Ann. Nucl. Energy, 94, 672-683.

3. Mosteller, R. (2014) Comparison of ENDF/BVII.1 and ENDF/B-VII.0 Results for the Expanded Criticality Validation Suite for MCNP and for Selected Additional Criticality Benchmarks, Nucl. Data. Sheets, 118, 442-445.

4. Ouahdani, S. El., Boukhal, H., Erradi. L., Chakir, E., Azahra, M and et al. (2018) A temperature effect analysis of the KRITZ-1 benchmark based on keff decomposition and using the JENDL-4.0 and ENDF/B-VII.1 libraries, Prog. Nucl. Energy, 109, 121-129.

5. Cornock, M. (2014) Benchmarking of ENDF/BVII.1 and JENDL-4.0 in the Fast Neutron Range, Nucl. Data Sheets, 118, 430-432.

6. Pritychenko, B. (2015) Calculations of Nuclear Astrophysics and Californium Fission Neutron Spectrum Averaged Cross Section Uncertainties Using ENDF/B-VII.1, JEFF-3.1.2, JENDL-4.0 and Low-fidelity Covariances, Nuclear. Data. Sheets, 123, 119-123.

7. Rafiei Karahroudi, M., Mousavi Shirazi, S.A. (2015) Study of power distribution in the CZP, HFP and normal operation states of VVER1000 (Bushehr) nuclear reactor core by coupling nuclear codes. Ann. Nucl. Energy, 75,
38-43.

8. Ouadie, K., Abdelouahed, C., Abdelhamid, J., Abdelaziz, D., Abdelmajid, Saidi. (2017) Processing and benchmarking of evaluated nuclear data file/b-viii.0 34 cross-section library by analysis of a series of critical experimental benchmark using the monte carlo code MCNP(X) and NJOY2016. Nucl. Eng. Technol. 49 (8), 1610-1616.

9. Rafiei Karahroudi, M., Mousavi Shirazi, S.A. (2014) Obtaining the neutronic and thermal hydraulic parameters of the VVER-1000 Bushehr nuclear reactor core by coupling nuclear codes. Kerntechnik. 79 (6), 528-531.

10. Dunn, W.L., Kenneth Shultis, J. (2012) Exploring Monte Carlo Methods. Academic Press is an imprint of Elsevier, USA. Chapter 10.

11. MacFarlane, R. E., Muir, D.W., Boicourt, R.M. (2012) The NJOY Nuclear Data Processing System, Version 2012, Los Alamos National Laboratory, USA.

12. Tsuneo, N., Keiichi, S., Satoshi, C., Tokio, F., Yutaka, $\mathrm{N}$ and et al. (1995) Japanese evaluated nuclear data library, version 3 revision-2; JENDL-3.2. J. Nucl. Sci. Technol. 32 (12), 12591271.

13. Shibata, K., Nakagawa, T., Sugano, H., Kawasaki, H. (1997) CURVES AND TABLES OF NEUTRON CROSS SECTIONS IN JENDL-3.2 PARTI ( $Z=1-50)$. Japan Atomic Energy Research Institute, JAERI-Data Code 97-003 (Part I), 1754.

14. Haeck, W., Verboomen, B. (2006) A Validated $\operatorname{MCNP}(X)$ Cross Section Library based on JEFF 3.1. Belgium, OPEN REPORT SCK • CEN-BLG1034 Rev. 0, 6-109.

15. Hoogenboom, J.E., Khotylev, A., Tholammakkil, M. (2007) Generation of MultiGroup Cross Sections and Scattering Matrices with the Monte Carlo Code Mcnp5. The Joint International Topical Meeting on Mathematics \& Computation and Supercomputing in Nuclear Applications. Monterey, USA 15-19 Apr, 1228- 1235.

16.Kerby, M., Mashnik, G. (2015) Total reaction cross sections in CEM and MCNP6 at intermediate energies. Nucl. Instrum. Methods Phys. Res. B. 356-357, 135-145.

Arab J. Nucl. Sci. \&Applic. Vol. 54, No. 1 (2021) 